\title{
A NOVEL COMPARISON OF STENTLESS VERSUS STENTED VALVES IN THE SMALL AORTIC ROOT
}

Vivek Rao, MD, PhD

George T. Christakis, MD

Jeri Sever, MSc

Stephen E. Fremes, MD

Gopal Bhatnagar, MD

Gideon Cohen, MD

Michael A. Borger, MD

Labib Abouzahr, MD

Bernard S. Goldman, MD
Background: Previous studies have compared prosthetic valves on the basis of industry-labeled valve sizes. Unfortunately, the relationship between the labeled size and the true measured external or internal diameter differs between valve manufacturers. Therefore hemodynamic comparisons between prosthetic valves are inaccurate if based solely on industry-labeled valve sizes. Methods: We have previously demonstrated that the internal diameter of a 21-mm Carpentier-Edwards pericardial stented valve is similar to that of a $25-\mathrm{mm}$ Toronto stentless porcine valve. Therefore we chose to compare postoperative hemodynamics in patients who received 19-, 21-, or 23-mm Carpentier-Edwards pericardial stented valves (inner diameter $18-22 \mathrm{~mm}, \mathrm{n}=69$ ) with those in patients who received 23- or $25-\mathrm{mm}$ stentless porcine valves (internal diameter 19-21 mm, $n=41)$. Results: Patients in the Carpentier-Edwards group were more likely to be elderly and more likely to require concomitant revascularization. Operative mortality was lower in the stentless porcine valve group $(0 \%$ vs $9 \%, P=.06)$. Hospital stay and ventilation requirements were shorter in the stentless porcine valve group. Postoperative hemodynamics were similar in the two groups. Conclusions: These data provide evidence that stentless and stented valves have similar hemodynamic profiles in the small aortic root when matched on true measured internal diameters. The clinical benefit of the stentless porcine valve may be due to patient selection or the lack of a rigid stent in the small aortic root, but it is not due to hemodynamic superiority over stented aortic valves of similar sizes. (J Thorac Cardiovasc Surg 1999;117:431-8)
$T^{1}$ he results of aortic valve replacement may be adversely affected by patient-prosthesis mismatch, especially in patients with small aortic roots. ${ }^{1-4}$ The poorer results may be due to residual postoperative gra-

From the Division of Cardiovascular Surgery, Sunnybrook Health Science Centre; University of Toronto, Toronto, Ontario, Canada. Awarded the 1998 Paul C. Samson Resident Manuscript Prize.

Supported by the Heart and Stroke Foundation of Canada (grant NA3026). V.R., G.C., and M.A.B. are Research Fellows of the Heart and Stroke Foundation of Canada. G.T.C. and S.E.F. are Research Scholars of the Heart and Stroke Foundation of Ontario.

Read at the Twenty-fourth Annual Meeting of The Western Thoracic Surgical Association, Whistler, British Columbia, June 24-27, 1998.

Received for publication July 15, 1998; revisions requested Aug 20, 1998; revisions received Sept 18, 1998; accepted for publication Nov 12, 1998.

Address for reprints: George T. Christakis, MD, Sunnybrook Health Science Centre, 2075 Bayview Ave, Suite H-406, Toronto, Ontario, Canada M4N 3M5.

Copyright (๑) 1999 by Mosby, Inc.

$0022-5223 / 99 \$ 8.00+0 \quad \mathbf{1 2 / 6 / 9 6 2 1 0}$ dients after surgery, which may adversely affect the regression of left ventricular mass and lead to lower long-term survival. ${ }^{5}$ Surgeons have intuitively attempted to insert the largest valve possible for any given annular dimension. The industry-labeled valve size is meant to provide information enabling the surgeon to judge whether an implanted valve is of adequate size for the patient. ${ }^{6}$ Experienced surgeons can then decide to choose a different prosthesis, perform an annular enlarging procedure,$^{3}$ or alternatively insert the valve in a supra-annular position.

When comparing bioprostheses from different manufacturers, most authors have stratified their analyses on the basis of the industry-labeled valve size. ${ }^{7-10}$ Unfortunately, recent reports have demonstrated a discrepancy between the labeled valve size and the actual dimensions of the valve or its sizer. ${ }^{11,12}$ Furthermore, in a previous study we demonstrated that the industrylabeled valve size bore no relation to any hemodynamically significant dimension and varied considerably among manufacturers. ${ }^{13}$ For example, the internal 


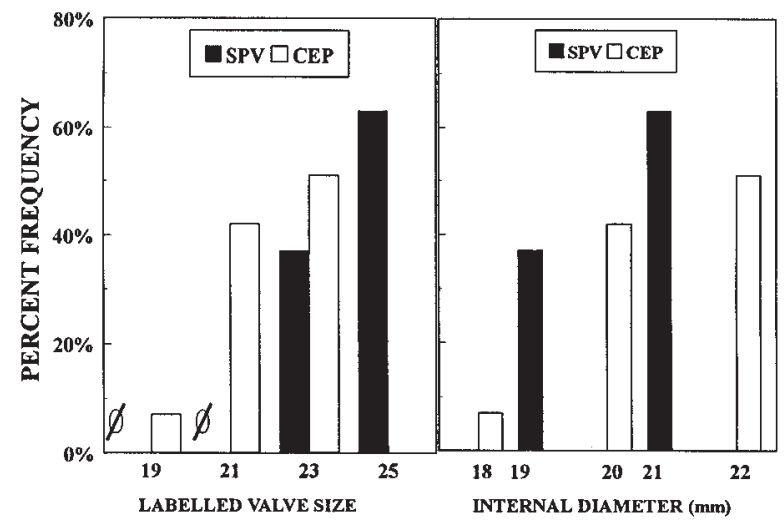

Fig 1. Distribution of valve sizes among 110 patients receiving small aortic bioprostheses. Left panel, Distribution of valves implanted based on manufacturer's labeled size. Right panel, Distribution of valves implanted based on measured internal diameter. The apparent discrepancy in valve sizes between groups is resolved when internal diameter is taken into consideration.

diameter of a $25-\mathrm{mm}$ Toronto stentless porcine valve (SPV; St Jude Medical, Inc, St Paul, Minn) is $21 \pm 2$ $\mathrm{mm}$ compared with $24 \pm 1 \mathrm{~mm}$ for a $25-\mathrm{mm}$ Carpentier-Edwards stented pericardial valve (CEP; Baxter Healthcare Corp, Edwards Division, Irvine, Calif). An internal diameter of $21 \mathrm{~mm}$ would roughly correspond to a size $21 \mathrm{CEP}$ valve. Similarly, a $25-\mathrm{mm}$ SPV has a measured external diameter of $25 \pm 1 \mathrm{~mm}$ compared with $32 \pm 1 \mathrm{~mm}$ for a $25-\mathrm{mm}$ CEP valve. Therefore we believe that it is meaningless to perform hemodynamic comparisons between prosthetic valves on the basis of the manufacturer's labeled valve sizes. This study presents a hemodynamic comparison of the SPV versus the CEP valve based on measured internal diameters. We chose to restrict our comparison to patients with small aortic roots because differences in valvular performance are most likely to affect outcomes in this high-risk subgroup.

\section{Methods}

We reviewed the case histories of all patients who underwent isolated aortic valve replacement (with or without coronary artery bypass grafting) and received either a Toronto SPV or a CEP valve between December 1, 1989, and October $1,1997(\mathrm{n}=236)$. There were 110 patients who received either an SPV $(n=41$ of $133,31 \%)$ or a CEP $(n=69$ of 103 , $67 \%$ ) with a measured internal diameter of less than $22 \mathrm{~mm}$. Fig 1 illustrates the distribution of valve sizes and measured internal diameters for each group.

A valvular database currently used at Sunnybrook Health Science Centre was used to collect preoperative, perioperative, and postoperative data on all patients in a prospective fashion. Clinical data were obtained prospectively on all 110 patients with a mean follow-up of $18 \pm 15$ months (range 160 months). Seven patients were lost to follow-up, of whom 4 were seen 1 year after the operation for their echocardiographic examination. Thus 1-year follow-up data are available on 103 of the original 110 patients $(97 \%)$.

The study protocol was approved by the Institutional Review Board of the Sunnybrook Health Science Centre. Patients who received the SPV during the investigational phase of the valve provided written, informed consent. Eligible patients received a bioprosthetic valve (for medical or lifestyle reasons) and were considered for either a stentless or stented valve. Patients with a greater than $10 \%$ discrepancy between the measured aortic anulus and the sinotubular junction were considered to be ineligible candidates for the SPV, as were patients with extensive calcific disease. The study population includes patients who are currently enrolled in a prospective, randomized trial comparing the SPV and CEP valves.

Operative technique. We have previously described our surgical and anesthetic techniques in detail. ${ }^{5}$ The technique for sizing and implanting valves including the Toronto SPV bioprosthesis has been well documented previously. ${ }^{14,15}$ All patients with documented coronary artery disease underwent concomitant revascularization at the time of aortic valve replacement. To maximize external validity, surgeons were permitted to use their preferred cardiopulmonary bypass and cardioplegic methods, which remained identical for each valve procedure.

Echocardiographic measurements. Echocardiography was performed before the operation, 3 to 6 months, and 12 to 15 months after the operation. Thirty-four (80\%) patients in the SPV group and 33 (41\%) patients in the CEP group had echocardiographic data at all time points. Examination included 2-dimensional, 2-dimensional derived M-mode, continuous wave, and pulsed Doppler and color Doppler analyses done with a Hewlett-Packard Sonos 1000 E echocardiographic machine (Hewlett-Packard Company, Andover, Mass) with a $2.5-\mathrm{MHz}$ transducer. Left parasternal, apical, periapical, right parasternal, subcostal, and suprasternal standard views were obtained in a step-by-step successive pattern of interrogation. All measurements were averaged from 3 cardiac cycles in sinus rhythm and performed by only 2 sonographers who were previously assessed and confirmed for less than $5 \%$ interobserver variability. ${ }^{5}$

Left ventricular mass was calculated from 2-dimensional derived M-mode measurements taken according to the American Society of Echocardiography recommendations. Left ventricular mass indexed on body surface area (LVMI) provides a noninvasive and highly reproducible estimate of the extent of left ventricular hypertrophy. LVMI is a reflection of the severity of aortic stenosis and has been positively correlated to peak aortic valve gradients. ${ }^{16}$ LVMI has previously been shown to regress early after aortic valve replacement, but residual left ventricular hypertrophy is present in most patients and may be related to the presence of a rela- 
Table I. Preoperative clinical information

\begin{tabular}{lccc}
\hline & $\begin{array}{c}S P V \\
(n=41)\end{array}$ & $\begin{array}{c}\text { CEP } \\
(n=69)\end{array}$ & P value \\
\hline Elderly (>70 y) & $13(32)$ & $58(84)$ & .001 \\
Female sex & $28(68)$ & $35(51)$ & .07 \\
LVEF < 40\% & $2(5)$ & $10(14)$ & .12 \\
Concomitant revascularization & $13(32)$ & $40(58)$ & .008 \\
Redo sternotomy & $1(2)$ & $6(9)$ & .25 \\
Aortic valve disease & & & .70 \\
$\quad$ Stenosis & $30(73)$ & $47(68)$ & \\
$\quad$ Regurgitation & $3(7)$ & $11(16)$ & \\
$\quad$ Mixed disease & $8(20)$ & $9(13)$ & \\
$\quad$ Prosthetic valve dysfunction & $0(0)$ & $2(3)$ & \\
Body surface area (m ${ }^{2} \pm$ SD) & $1.8 \pm 0.2$ & $1.8 \pm 0.2$ & .76 \\
\hline
\end{tabular}

Number and percentages (parentheses). $L V E F$, Left ventricular ejection fraction.

tively stenotic aortic valve prosthesis. ${ }^{5,17,18}$ Measurements of effective orifice area, peak and mean transvalvular pressure gradients, and LVMI were calculated with the use of previously published formulas. ${ }^{14}$

Statistical analysis. Statistical analyses were performed with the use of the SAS program (SAS Institute, Inc, Cary, NC). Perioperative demographics were compared by means of $\chi^{2}$ or Fisher's exact test for categoric variables and analysis of variance (ANOVA) for continuous variables. Hemodynamic comparisons between prosthetic groups were performed by means of 2-way repeated-measures ANOVA with the main effects of time, group, and internal diameter on each outcome. Continuous data are presented as the mean \pm $\mathrm{SD}$ with figures illustrating standard error bars. Actuarial survival was calculated by means of the Kaplan-Meier method with Mantel-Cox regression analysis to compare survival between groups and illustrated as smoothed estimates of survival at 6-month intervals after the operation. Exact $P$ values are provided for each comparison.

\section{Results}

Patient population. Table I illustrates the preoperative patient demographics for each group. Patients in the SPV group were younger ( $62 \pm 14$ vs $75 \pm 6$ years, $P=.0001)$ and were less likely to undergo simultaneous coronary revascularization. There were no significant differences in gender, preoperative left ventricular function, aortic valve disease, or body surface area.

Perioperative clinical outcomes. Table II summarizes the intraoperative and early postoperative data. The aortic occlusion and cardiopulmonary bypass times were similar in each group. No deaths occurred in the SPV group, whereas 6 deaths occurred in the CEP group $(P=.06)$. Ventilation requirements were significantly shorter in the SPV group (14 \pm 11 hours, range 368 hours) than in the CEP group ( $24 \pm 41$ hours, range 3-266 hours). Similarly, postoperative length of stay

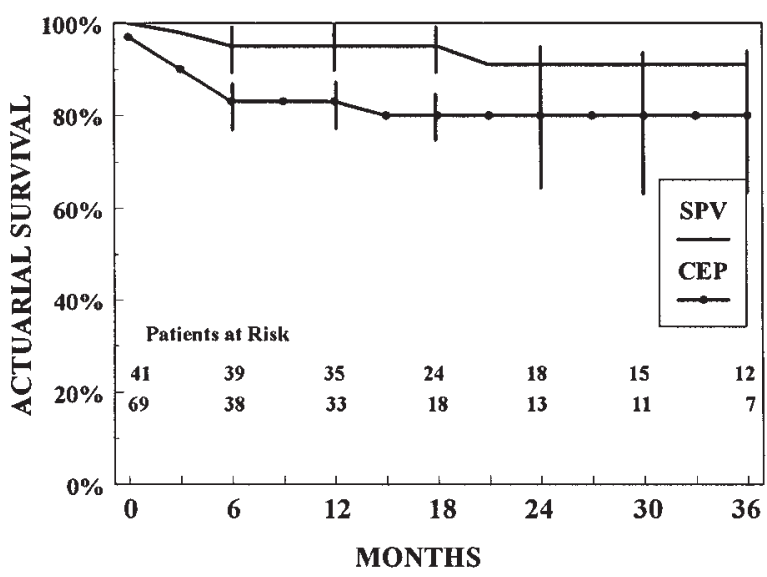

Fig 2. Actuarial survival in patients receiving a Toronto SPV or a CEP valve. Cox-Wilcoxon regression analysis demonstrates a significant difference in actuarial survival $(P=.055)$.

Table II. Perioperative data

\begin{tabular}{lccc}
\hline & $\begin{array}{c}S P V \\
(n=41)\end{array}$ & $\begin{array}{c}\text { CEP } \\
(n=69)\end{array}$ & P value \\
\hline Aortic crossclamp time (min) & $125 \pm 24$ & $116 \pm 34$ & .17 \\
Cardiopulmonary bypass time & $148 \pm 30$ & $151 \pm 48$ & .74 \\
$\quad($ min) & & & \\
Postoperative stroke, No. (\%) & $1(2)$ & $4(6)$ & .65 \\
Permanent cardiac pacing, No. & $1(2)$ & $9(13)$ & .09 \\
$\quad(\%)$ & & & \\
Blood transfusion, No. (\%) & $40(98)$ & $63(91)$ & .25 \\
Ventilation requirements (h) & $14 \pm 11$ & $27 \pm 42$ & .02 \\
ICU stay (h) & $51 \pm 50$ & $51 \pm 44$ & .99 \\
Postoperative stay (d) & $8 \pm 5$ & $10 \pm 7$ & .05 \\
Operative mortality, No. (\%) & $0(0)$ & $6(9)$ & .06 \\
\hline
\end{tabular}

Results are expressed as mean \pm SD unless otherwise specified; Fisher's exact test for categoric values, the Student $t$ test for continuous variables. ICU, Intensive care unit.

was shorter in the SPV group ( $8 \pm 5$ days, range 4-28 days, vs $11 \pm 7$ days, range 5-43 days; $P=.05$ ). Fig 2 illustrates actuarial survival in both groups (inclusive of perioperative mortality). At 36 months, survival in the CEP group was $80 \% \pm 6 \%$ compared with $91 \% \pm 5 \%$ in the SPV group ( $P=.055$ by Wilcoxon). There were 3 late deaths in the SPV group, all due to complications of stroke. There were 4 late deaths in the CEP group. Two late deaths in the CEP group were due to complications of stroke and 1 was due to a myocardial infarction. The fourth late death occurred in a patient who underwent reoperation for prosthetic valve endocarditis 14 months after the initial operation.

Postoperative hemodynamics. Fig 3 illustrates the mean pressure gradient for each valve group with time. No significant differences in mean pressure gradient 


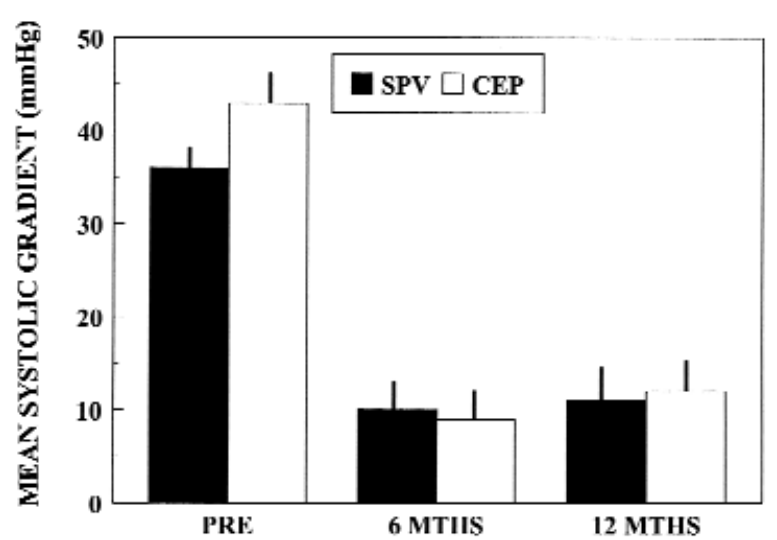

Fig 3. Mean systolic gradients after aortic valve replacement with a Toronto SPV or a CEP valve.

were noted between groups at any time point. Repeated-measures ANOVA demonstrated no interactive effect between group and time, a significant decrease in mean gradient with time (time effect: $\mathrm{F}=$ $68, P=.0001)$, but no significant differences resulting from group (group effect: $\mathrm{F}=2, P=.15$ ) or internal diameter (size effect: $\mathrm{F}=1.14, P=.29$ ). Fig 4 demonstrates calculated effective orifice areas for each valve group over time. There was no interactive effect between group and time, nor were there significant differences in calculated effective orifice areas between groups (group effect: $\mathrm{F}=0.63, P=.43$ ). However, repeated-measures ANOVA demonstrated a significant time effect $(\mathrm{F}=58, P=.0001)$ and size effect $(\mathrm{F}=11.7$, $P=.009$ ). Figs 5 and 6 illustrate the regression in LVMI with time after aortic valve replacement. There was a significant reduction in LVMI in both groups during the first 6 months after the operation, with little further reduction occurring in the subsequent 6 months. There were no significant interactive effects between group and time. However, there was a significant effect of internal diameter on the regression of LVMI (size effect: $\mathrm{F}=5.2, P=.02$ ) and a significant difference between groups (group effect: $\mathrm{F}=15.8, P=.0001$ ).

Table III illustrates a hemodynamic comparison between a 25-mm SPV (21-mm internal diameter) and a 21-mm CEP valve (20-mm internal diameter). At 6 months after the operation, there were no significant differences in peak or mean systolic gradients nor in the regression in LVMI. However, calculated effective orifice areas were larger in the similarly sized SPV valves $\left(1.5 \pm 0.3 \mathrm{~cm}^{2}\right.$ vs $\left.1.2 \pm 0.3 \mathrm{~cm}^{2}, P=.01\right)$.

\section{Discussion}

Aortic valve replacement remains the definitive treatment for critical aortic stenosis and for aortic insuffi-

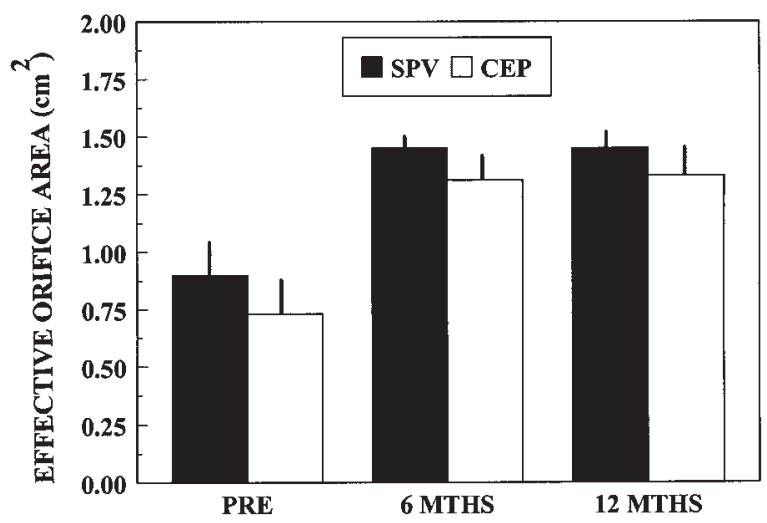

Fig 4. Calculated effective orifice areas after aortic valve replacement with a Toronto SPV or a CEP valve.

ciency with left ventricular dilatation. Unfortunately, elderly patients with small aortic roots are at risk for prosthesis-patient mismatch if they receive a conventional stented bioprosthesis. Surgeons use the manufacturer's labeled valve size as an index of the adequacy of a prosthetic valve's effective orifice area. Intuitively, surgeons avoid inserting 19- or 21-mm bioprostheses in patients with a body surface area above $1.7 \mathrm{~m}^{2} .2,9,10$

The alternatives to implanting a small bioprosthesis include mechanical valve replacement, patch enlargement of the aortic anulus, ${ }^{3}$ or implantation of a stentless bioprosthesis. ${ }^{15,19}$ Mechanical valves have a proportionally larger effective orifice area for a given anulus size and have been shown to produce lower gradients when compared with similarly sized bioprostheses. ${ }^{8,10}$ However, elderly patients are at increased risk for anticoagulant-related hemorrhage; therefore mechanical valve replacement may be inadvisable. Sommers and David ${ }^{3}$ demonstrated that anulus-enlarging procedures resulted in long-term survivals comparable with those of patients receiving larger aortic prostheses; however, the operative mortality of aortic valve replacement increased from $3.5 \%$ to $7.1 \%$ when enlargement of the aortic anulus was performed.

Sintek and colleagues ${ }^{20}$ implanted 27 Freestyle stentless porcine valves (Medtronic, Irvine, Calif) in patients with small aortic anuli. At 1 year after the operation, the mean systolic gradient ranged from 2.2 to $19.3 \mathrm{~mm} \mathrm{Hg}$ for size $19-$ and $21-\mathrm{mm}$ valves. These results are similar to the findings of our present study. However, to date no patient at our institution has received a 19- or 21-mm SPV bioprosthesis. Sintek's group uses the subcoronary technique for implantation of the Freestyle valve, which is the technique used to implant the Toronto SPV bioprosthesis. Therefore, how do surgeons compare the results of aortic valve replace- 


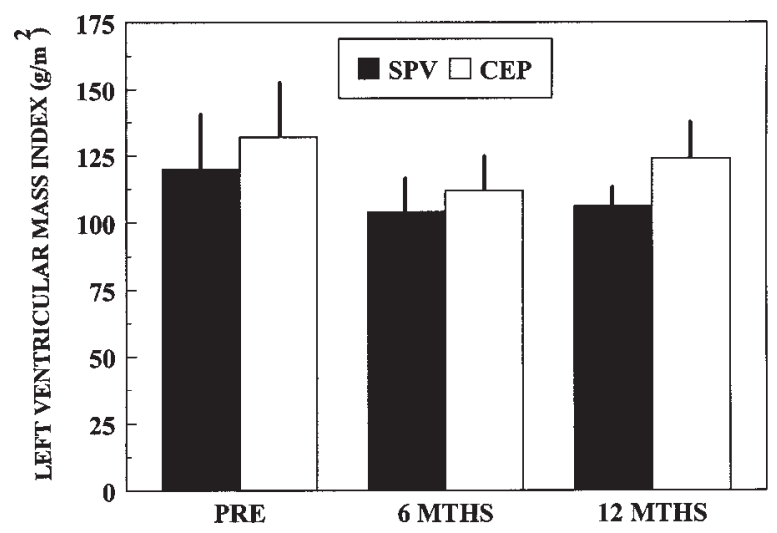

Fig 5. LVMI after aortic valve replacement with a Toronto SPV or a CEP valve. There was a significant reduction in LVMI in both groups during the first 6 months after the operation with little further reduction occurring in the ensuing 6 months.

ment in small aortic roots when one center is implanting 23- and 25-mm SPV bioprostheses and another center is implanting 19- and 21-mm Freestyle valves? It would appear logical that implantation of a larger valve should result in improved postoperative hemodynamics, but our gradients are similar to those reported by Sintek and colleagues. ${ }^{19,20}$ The explanation for this apparent discrepancy is that the internal diameter of a 19-mm Medtronic Freestyle valve is similar to that of a 23-mm Toronto SPV bioprosthesis. When one compares valves on the basis of measured internal diameters, the hemodynamic parameters more closely reflect the intrinsic properties of the valve versus confounding effects resulting from an arbitrary manufacturer-based labeling system.

Fig 1 provides further evidence to support the discrepancy between labeled valve sizes and measured internal diameters. The left panel would suggest that in this nonrandomized cohort, we were selectively inserting larger valves in the SPV group. In fact, previous publications from our group and others have consistently found that the SPV valve "allowed" for the implantation of a 2- to 4-mm larger valve., 5,14 However, the right panel of Fig 1 clearly indicates that similar sized valves were implanted in both groups.

Furthermore, the CEP and other stented valves can be potentially inserted in a supra-annular position, allowing the bulk of cuff tissue to fill the aortic sinuses. Thus it is possible to implant a Toronto SPV and a CEP valve with dissimilar external diameters, but similar internal diameters, into the same anulus. The external diameter in this situation would not accurately reflect the size of the valve being implanted and may not predict postop-

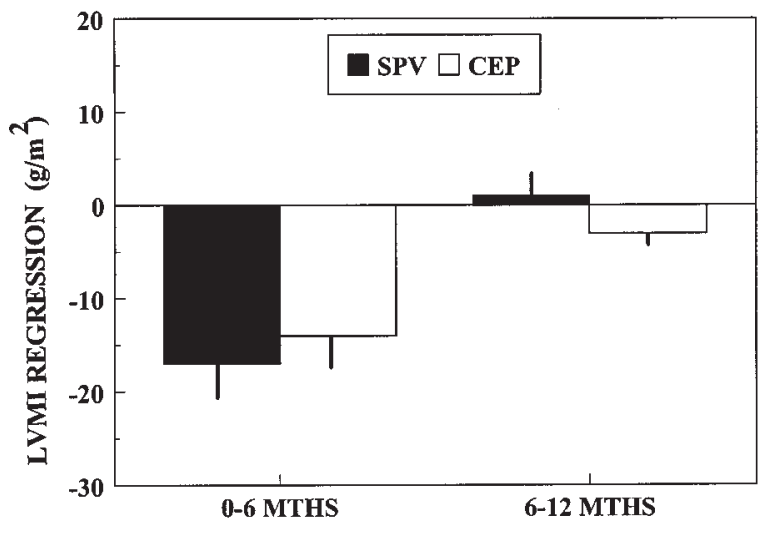

Fig 6. The regression in LVMI after aortic valve replacement with a Toronto SPV or a CEP valve. There was a significant regression in LVMI in both groups during the first 6 months after the operation with little further reduction occurring in the ensuing 6 months.

Table III. Postoperative hemodynamic data for 25-mm Toronto SPV (21-mm internal diameter) and 21-mm $C E P$ valve (20-mm internal diameter)

\begin{tabular}{lccc}
\hline & $\begin{array}{c}25-m m \text { SPV } \\
(n=26)\end{array}$ & $\begin{array}{c}21-m m \text { CEP } \\
(n=29)\end{array}$ & P value \\
\hline Peak systolic gradient $(\mathrm{mm} \mathrm{Hg})$ & & & \\
$\quad$ Preoperative & $53 \pm 32$ & $59 \pm 23$ & .69 \\
$\quad$ Six months & $18 \pm 7$ & $17 \pm 4$ & .69 \\
$\quad$ One year & $18 \pm 6$ & $21 \pm 6$ & .26 \\
Mean systolic gradient (mm Hg) & & & \\
$\quad$ Preoperative & $34 \pm 33$ & $36 \pm 17$ & .88 \\
$\quad$ Six months & $10 \pm 5$ & $9 \pm 4$ & .45 \\
$\quad$ One year & $9 \pm 6$ & $12 \pm 5$ & .23 \\
Effective orifice area $\left(\mathrm{cm}^{2}\right)$ & & & \\
$\quad$ Preoperative & $1.0 \pm 0.4$ & $0.8 \pm 0.3$ & .26 \\
$\quad$ Six months & $1.5 \pm 0.3$ & $1.2 \pm 0.3$ & .01 \\
$\quad$ One year & $1.6 \pm 0.3$ & $1.3 \pm 0.2$ & .03 \\
LVMI & & & \\
$\quad$ Preoperative & $136 \pm 36$ & $115 \pm 29$ & .08 \\
$\quad$ Six months & $110 \pm 23$ & $107 \pm 35$ & .84 \\
$\quad$ One year & $109 \pm 26$ & $105 \pm 24$ & .66 \\
\hline
\end{tabular}

Results are expressed as mean \pm SD.

erative gradients. We believe that the internal diameter is the only consistent, reproducible measurement that can allow for accurate hemodynamic comparisons between valves.

In this study, we compared the SPV and CEP valves on the basis of internal diameters. Thus 23- and 25-mm Toronto SPV bioprostheses (manufacturer's sizes) were compared with 19-, 21-, and 23-mm CEP valves. The mean labeled size implanted in each group was significantly larger for SPV bioprostheses ( $24.2 \pm 1$ vs $21.9 \pm$ $1, P<.001)$. In contrast, the mean internal diameter was 
larger in the CEP group $(20.9 \pm 0.3$ vs $20.2 \pm 1.0, P=$ $.009)$. All of these valves have internal diameters ranging from 18 to $22 \mathrm{~mm}$. In contrast, the external diameter for the SPV bioprostheses studied in this series ranged from 23 to $25 \mathrm{~mm}$ compared with 26 to $30 \mathrm{~mm}$ for the CEP valves. For a "labeled" valve size of $23 \mathrm{~mm}$, the difference in external diameter between groups is 7 $\mathrm{mm}$. One would expect that such a large discrepancy would result in significant hemodynamic differences between groups. The fact that there were no differences in gradients between groups lends further evidence to our contention that the internal diameter of a prosthetic valve is the most important predictor of postoperative hemodynamics. Furthermore, a supra-annular implantation of a 21-mm CEP valve would yield a larger internal diameter than a subcoronary implantation of a $23-\mathrm{mm}$ SPV bioprosthesis. Thus implantation of a $23-\mathrm{mm}$ valve (manufacturer's label) in a patient with a large body surface area does not preclude patient-prosthesis mismatch unless the internal diameter of the valve being implanted is taken into consideration.

Our analyses revealed that patients who received a "small-sized" 25-mm Toronto SPV bioprosthesis displayed significantly greater effective orifice areas with time. Despite this increase in effective orifice area, there were no appreciable differences in gradients or mass regression. The calculated power to detect a difference at the 5\% $\alpha$-level was relatively high: $93 \%$ power to detect a $5-\mathrm{mm}$ difference in peak gradient; $91 \%$ to detect a 3-mm difference in mean gradient; $98 \%$ to detect a $20 \mathrm{~g} / \mathrm{m}^{2}$ difference in left ventricular mass, and $99 \%$ to detect a $0.1 \mathrm{~cm}^{2}$ difference in effective orifice area.

However, this report and previous studies from other investigators have demonstrated superior clinical results in patients receiving the SPV bioprosthesis. ${ }^{14,15}$ Because of the investigational nature of our early experience with this valve, it is possible that differences in clinical outcomes may be simply due to patient selection. Patients who received SPV bioprostheses were younger and were less likely to require myocardial revascularization. As a result, despite the more technically demanding implantation of an SPV bioprosthesis, overall aortic occlusion and cardiopulmonary bypass times were not different between groups. Additional follow-up is required to determine whether the observed survival benefit persists with time. David and associates ${ }^{21}$ recently reported a case-matched cohort study that demonstrated improved survival in patients who received an SPV bioprosthesis. We are currently involved in a prospective randomized clinical trial comparing the SPV and CEP valves with respect to hemo- dynamic parameters. The randomized design of this study should provide further information with regard to a potential survival benefit among patients who receive a stentless valve.

The ability of a stentless valve to allow dynamic expansion of the aortic root may be the mechanism resulting in increased effective orifice areas. Further study is required to determine whether this property of stentless valves allows for implantation of small valves in small anuli with no adverse hemodynamic or clinical sequelae.

Our study is limited by the relatively small sample size and short follow-up. Unfortunately, small aortic valves are implanted in fewer than $50 \%$ of patients undergoing aortic valve replacement. Furthermore, the retrospective nature of this study introduces potential bias despite the fact that all clinical and hemodynamic data were collected prospectively as part of our routine valvular follow-up.

Our arbitrary cut point for the internal diameter resulted in the inclusion of 23-mm CEP valves and the exclusion of 27-mm SPV bioprostheses (labeled sizes). The size ranges defined in this study included $31 \%$ of all SPV bioprostheses implanted compared with $67 \%$ of all CEP valves inserted during the same period. This may have biased the hemodynamic results against the SPV bioprosthesis as the average internal diameter was larger in the CEP group. However, the direct comparison based on internal diameter (Table III) demonstrates the expected result that similar sized valves produce similar postoperative hemodynamics.

In summary, we conclude that hemodynamic comparisons between prosthetic valves are inaccurate if based solely on the manufacturer's labeled size. More meaningful comparisons can be made prospectively if surgeons compare the actual size of different valvular substitutes that they would implant in a given patient. However, this decision is highly surgeon-specific and may be influenced by a surgeon's willingness to perform an anulus-enlarging procedure or to implant the valve in a supra-annular position. Given these shortcomings, we believe that the most reliable and reproducible measurement of valve size remains the internal diameter. We suggest that future comparisons of prosthetic valves should be based on this measure of valve size such that differences between valves can be attributed to their intrinsic properties versus artifact caused by arbitrary labeling.

\section{REFERENCES}

1. Sawant D, Singh AK, Feng WC, Bert AA, Rotenberg F. Nineteen millimeter aortic St. Jude Medical heart valve prosthesis: up to sixteen years' follow-up. Ann Thorac Surg 1997;63:964-70. 
2. Christakis GT, Goldman BS. Do small aortic valves influence long-term survival? Ann Thorac Surg 1997;63:933-4.

3. Sommers KE, David TE. Aortic valve replacement with patch enlargement of the aortic annulus. Ann Thorac Surg 1997;63: 1608-12.

4. He GW, Grunkemeier GL, Gately JL, Furnary AP, Starr A. Up to thirty-year survival after aortic valve replacement in the small aortic root. Ann Thorac Surg 1995;59:1056-62.

5. Christakis GT, Joyner CD, Morgan CD, et al. Left ventricular mass regression early after aortic valve replacement. Ann Thorac Surg 1996;62:1084-9.

6. Pibarot P, Honos GN, Durand LG, Dumesnil JG. The effect of prosthesis-patient mismatch on aortic bioprosthetic valve hemodynamic performance and patient clinical status. Can J Cardiol 1996; $12: 379-87$.

7. Fiore AC, Swartz M, Grunkemeier GL, et al. Valve replacement in the small aortic annulus: prospective randomized trial of St. Jude with Medtronic Hall. Eur J Cardiothorac Surg 1997;11:485-91.

8. Noera G, Pensa P, Lamarra M, Mascagni R, Cremonesi A, Balestra G. Hemodynamic evaluation of the Carbomedics R, St. Jude Medical HP and Sorin-Bicarbon valve in patients with small aortic annulus. Eur J Cardiothorac Surg 1997;11:473-5.

9. Gonzalez-Juanatey JR, Garcia-Acuna JM, Vega Fernandez M, et al. Influence of the size of aortic valve prostheses on hemodynamics and change in left ventricular mass: implications for the surgical management of aortic stenosis. J Thorac Cardiovasc Surg 1997:112:273-80.

10. Gonzalez-Juanatey JR, Garcia-Acuna JM, Vega Fernandez M, et al. Hemodynamics of various designs of $19 \mathrm{~mm}$ pericardial aortic valve bioprosthesis. Eur J Cardiothorac Surg 1996;10:201-6.

11. Cochran RP, Kunzelman KS. Discrepancies between labeled and actual dimensions of prosthetic valves and sizers. J Card Surg 1996;11:318-24.

12. Bonchek LI, Burlingame MW, Vazales BE. Accuracy of sizers for aortic valve prostheses. J Thorac Cardiovasc Surg 1987;94:632-8.

13. Christakis GT, Buth KJ, Goldman BS, et al. Inaccurate and misleading valve sizing: a proposed standard for valve size nomenclature. Ann Thorac Surg 1998;66:1198-203.

14. Cohen G, Christakis GT, Buth KJ, et al. Early experience with stentless versus stented valves. Circulation 1997;96(Suppl):II7682.

15. David TE, Pollick C, Bos J. Aortic valve replacement with stentless porcine aortic bioprosthesis. J Thorac Cardiovasc Surg 1990; 99:113-8.

16. Salcedo EE, Korzick DH, Currie PJ, Stewart WJ, Lever HM, Goormastic M. Determinants of left ventricular hypertrophy in patients with aortic stenosis. Cleve Clin J Med 1989;56:590-6.

17. Krayenbuehl HP, Hess OM, Monrad ES, Schneider J, Mall G, Turina M. Left ventricular myocardial structure in aortic valve disease before, intermediate and late after aortic valve replacement. Circulation 1989;79:744-5.

18. De Paulis R, Sommariva L, De Matteis GM, et al. Extent and pattern of regression of left ventricular hypertrophy in patients with small size Carbomedics aortic valves. J Thorac Cardiovasc Surg 1997;113:901-9.

19. Sintek CF, Fletcher AD, Khonsari S. Stentless porcine aortic root: Valve of choice for the elderly patient with small aortic root? J Thorac Cardiovasc Surg 1995;109:871-6.

20. Sintek CF, Fletcher AD, Khonsari S. Small aortic root in the elderly: use of stentless bioprosthesis. J Heart Valve Dis 1996;5: S308-13.
21. David TE, Puschmann R, Ivanov J, Bos J, Armstrong S, Feindel $\mathrm{CM}$, et al. Aortic valve replacement with stentless and stented porcine valves: a case-match study. J Thorac Cardiovasc Surg $1998 ; 116: 236-41$

\section{Discussion}

Dr Colleen F. Sintek (Los Angeles, Calif). I would like to congratulate the authors on once again contributing to our understanding of valve sizing and hemodynamics.

Since the introduction of stentless valves, many authors have reported on the excellent hemodynamics, with low transvalvular gradients that increase only slightly with exercise, and superior effective orifice areas.

The small nonrandomized study that you have presented concludes that the Toronto SPV and the stented CEP valves have similar hemodynamic profiles in the smaller valve sizes when compared on the basis of internal diameter size.

I have several concerns regarding the conclusions. First, as a practicing surgeon, I want to know what size of each prosthetic valve I can implant for a given anulus size. Therefore, my first question is: Wouldn't it be more appropriate to compare valves on the basis of patient anulus size rather than internal diameter?

Dr Rao. That's an excellent question, and we are addressing that issue in a current, prospective trial. We believe that the most accurate method to compare valve sizes is to ask the surgeon, who remains blinded to valve group before insertion, which valve size in each group would he or she insert on the basis of the patient's anulus. Unfortunately, this comparison is confounded between surgeons and between centers in that some surgeons may elect to do a supra-annular insertion of a given valve to increase the implanted size. In contrast, a different surgeon may elect to perform an anulus-enlarging procedure. Given these shortcomings, we believe that the only reliable indicator of postoperative hemodynamics comparable across centers and across surgeons is the internal diameter of the valve. This measurement is not affected by the site at which the valve is inserted within the outflow tract, and it represents the maximal orifice area that can be achieved in that patient.

Dr Sintek. In a patient in whom you can implant a size 25 SPV bioprosthesis, would that patient receive a size 21 pericardial valve, or would he or she receive a larger size or a smaller size pericardial valve?

Dr Rao. Given an identical root, where both the SPV and a stented valve can be placed, our data would suggest that a 23-mm stented valve would yield a larger internal diameter than a 25-mm SPV bioprosthesis. The surgeon may have to resort to implanting the stented valve in a supra-annular position to safely accommodate a $23-\mathrm{mm}$ prosthesis. A 21-mm intra-annular stented valve would yield a similar internal diameter to a 25-mm SPV bioprosthesis.

However, an important point is whether there is an intrinsic benefit to a stentless design that might lead to improved postoperative hemodynamics. If a surgeon believes that the benefits of a dynamic, expansile aortic root outweigh the 
small difference in valvular size, a stentless valve may be the preferred prosthesis.

Dr Sintek. Am I correct that you ordinarily would upsize by $2 \mathrm{~mm}$ on a stentless valve?

Dr Rao. That's correct.

Dr Sintek. My second concern is that you have lumped all the valve sizes of the Toronto SPV bioprosthesis as well as the pericardial prosthesis together in your analysis. As you stated in your manuscript and showed on one of your slides, the data are actually biased in favor of the pericardial valve, as more than $50 \%$ of the pericardial data were collected from valves with a 22-mm internal diameter, larger than the Toronto valves. I am not sure that your conclusion that the valves are hemodynamically equivalent is correct. In fact, when you matched internal diameters comparing the size 25 SPV bioprosthesis against the size 21 CEP valve, you did show a larger effective orifice area with the Toronto valve. In my interpretation of your left ventricular mass regression data for those 2 valve sizes, the $25-\mathrm{mm}$ SPV versus the $21-\mathrm{mm}$ CEP, there was significantly greater left ventricular mass regression from 64-g decrease in the Toronto valve versus only a $12-\mathrm{g}$ decrease in the pericardial size 21 valve at 1 year's follow-up. Could you comment on that?

Dr Rao. We agree with your conclusion. The basis of our study design originated in previous studies in which we stratified by labeled valve size. We found no differences in postoperative gradients, yet there was a persistent difference in effective orifice areas and left ventricular mass regression. The only way we could account for this was to assume that valves with similar sized internal diameters would yield similar peak and mean gradients and that the differences in effective orifice areas and the regression of left ventricular mass were due to the effect of a rigid stent. I think we agree that stentless valves have beneficial effects that are independent of the fact that a larger valve can be inserted, because our data show clearly that similar sized valves are being implanted.

Dr Sintek. My next concern is your analysis of your clinical results. As you pointed out, there were no surgical deaths in the Toronto group, yet 6 patients died in the pericardial group. I am not sure that we can attribute this huge difference to patient factors alone; in fact, they may very well be due to valve-related factors. Certainly if you have a residual transvalvular gradient in the early postoperative period, these patients may have low cardiac output syndrome and be prone to the development of multiorgan system failure.

Did these deaths occur in the patients with smaller pericardial valves, that is, the $19-\mathrm{mm}$ valves?

Dr Rao. Most of the deaths actually occurred in patients receiving the 21-mm CEP valves, and 4 of the 6 were due to stroke. The 4 late deaths in the CEP group were due to stroke $(n=2)$, myocardial infarction $(n=1)$, or endocarditis $(n=1)$.
Dr Sintek. Finally, you commented on the differences in valve sizing between the Toronto and the Medtronic Freestyle stentless valves. Over the past $5 \frac{1}{2}$ years our group has implanted more than 100 of the Freestyle valves. In 34 of our patients we have implanted size 19 or 21 valves. In our experience we can always upsize by $2 \mathrm{~mm}$; in other words, we insert a 2-mm larger Freestyle valve on the basis of the manufacturer's labeled size as compared to any of the stented bioprostheses. For a size 21 valve, we get an effective orifice area of $1.5 \mathrm{~cm}^{2}$, and with our sizing system that should be compared with a 19-mm pericardial valve, because that is what we can place in that given patient's anulus. The effective orifice area for that valve is $1.1 \mathrm{~cm}^{2}$.

Thus, in these small valve sizes, I think the Medtronic Freestyle valve definitely has better hemodynamics than the pericardial valve, and it appears to have possibly better hemodynamics than the Toronto valve. Could you comment on that?

Dr Rao. Our center does not have experience with the Freestyle valve, but we certainly read with interest your work in that area. Again, you ask which valve should be inserted in a given patient's anulus and what the surgeon would have to do to insert a larger valve (ie, an anulus-enlarging procedure or a supra-annular placement of the valve). To answer that question, you have to know the intrinsic properties of the valve. I think we both agree that if you know the internal diameter of the valve that you are proposing to implant, then you can make the best decision as to which valve, which size, and which procedure you should do.

Dr Sintek. In your series you expressed the belief that a calcified aortic root was a contraindication to placing a Toronto SPV bioprosthesis. In our experience with the Freestyle valve, we have in fact felt that patients who have calcified aortic roots are ideal candidates, because the Freestyle valve can be seated much more safely without the possibility of disrupting the calcified aortic root and the possibility of breaking off calcific debris, which could lead to a higher postoperative stroke rate. Perhaps you could comment on that.

Dr Rao. We do not have any experience with the Freestyle valve, but we are certainly concerned with the placement of an SPV bioprosthesis in the calcific aortic root because of the potential for a paravalvular leak. Using a Freestyle valve with a mini-root replacement may obviate that concern; however, this entails a more complicated procedure with higher morbidity and mortality in the average surgeon's hands.

Dr Sintek. The other advantage with the Freestyle valve is that it can be trimmed down to within just a couple of millimeters of the anulus, so that the distal suture line is really actually just above the patient's anulus, which can be decalcified as the anulus is being prepared for the proximal suture line. That indeed is what we have done in that situation. 